\title{
Structural and Magnetic Properties of Cr-Co Nanoferrite Particles
}

\author{
Mamilla Lakshmi1 ${ }^{1}$, Katrapally Vijaya Kumar2*, Krishnan Thyagarajan ${ }^{3}$ \\ ${ }^{1}$ Marri Laxman Reddy Institute of Technology \& Management, Dundigal, Hyderabad, India \\ ${ }^{2}$ Department of Physics, JNTU Hyderabad College of Engineering Jagtial, Karimnagar, India \\ ${ }^{3}$ Department of Physics, JNTU Anantapur College of Engineering Pulivendula, Pulivendula, India \\ Email: ${ }^{*}$ kvkphd@gmail.com
}

Received 23 December 2015; accepted 19 February 2016; published 22 February 2016

Copyright (C) 2016 by authors and Scientific Research Publishing Inc.

This work is licensed under the Creative Commons Attribution International License (CC BY).

http://creativecommons.org/licenses/by/4.0/

(c) (i) Open Access

\begin{abstract}
Nano-crystalline $\mathrm{Cr}_{x} \mathrm{CoFe}_{2-x} \mathrm{O}_{4}(x=0,0.1,0.2,0.3,0.4,0.5)$ ferrites were synthesized by sol-gel method. The X-ray diffraction patterns of all the samples provide information about the existence of single phase spinel structure. The SEM and TEM micrographs show the uniform particle distribution and SAED pattern represents the polycrystalline nature of the resultant ferrite nano-particles. High purity of the sample is confirmed by energy dispersive X-ray analysis. The FTIR spectra show two strong absorption bands in the range of $600-400 \mathrm{~cm}^{-1}$, which confirm the presence of M-O stretching band in ferrites. The magnetic properties of the synthesized samples were investigated by using vibrating sample magnetometer at room temperature. According to VSM reports the main magnetic parameters like saturation magnetization $\left(M_{s}\right)$, coercivity $\left(H_{c}\right)$ were found to decrease with the substitution of $\mathrm{Cr}^{3+}$ content. Possible mechanisms which are responsible for the results are scrutinized minutely in this paper.
\end{abstract}

\section{Keywords}

Sol-Gel Method, Magnetic Property, Cr-Co Nanoferrite Particles

\section{Introduction}

Spinel ferrite nano-particles with a high surface area have many technical applications in several fields such as high-density information storage, ferro-fluids, catalysts, drug targeting, hyperthermia, magnetic separation, and magnetic resonance imaging. The general formula of spinel ferrites is $\mathrm{AB}_{2} \mathrm{O}_{4}$. The spinel ferrite structure is based on a closed-pack oxygen lattice, in which tetrahedral (A sites) and octahedral (B sites) interstices are oc-

${ }^{*}$ Corresponding author. 
cupied by the cations. Spinels with only divalent ions in tetrahedral sites are called normal, while compounds with the divalent ions in the octahedral sites are called inverse. The interesting properties of the spinel ferrites originate mainly from the interactions between cations that are located in the tetrahedral (A) and the octahedral (B) sites [1] [2]. $\mathrm{CoFe}_{2} \mathrm{O}_{4}$ exhibits an inverse spinel stricture with the $\mathrm{Co}^{2+}$ ions present in the $\mathrm{B}$ sites and $\mathrm{Fe}^{3+}$ ions distributed almost equally between the A and B sites [3]. Cobalt ferrite is a familiar hard magnetic material with high coercivity, moderate magnetization and good magnetostrictive properties among all the ferrite family. These properties along with its great physical and chemical stabilities make Co-ferrite nano-particles be suitable for many technical applications [4]. Their applications include high frequency devices, memory cores, high density information storage and also in biomedical field [5] [6].

The identification of new materials with enhanced properties or new synthesis techniques to improve the performance of existing materials, along with the cost-effective advantages, is always an interesting matter for researchers. Accordingly, we have tried to improve the intrinsic properties of Co-ferrite with the successive increased substitution of $\mathrm{Cr}^{3+}$ ions through sol-gel method. The spinel ferrites also allow introduction of different metal ions, which can modify the magnetic and electric properties considerably. For example, due to the antiferromagnetic nature of $\mathrm{Cr}$ ions, there is a possibility of achieving control over the main magnetic parameters like remanence and coercivity in developing technologically important materials by simple substitution of $\mathrm{Cr}$ ions in $\mathrm{AB}_{2} \mathrm{O}_{4}$ [7].

It is well known that several chemical techniques, such as hydrothermal [8], co-precipitation [9] and sol-gel [10] synthesis have been used to prepare ultrafine ferrite powders. Among these techniques, sol-gel method offers high degree of compositional homogeneity content in a relatively short processing time at a very low temperature [11]. An understanding of the relationship between structure, particle size and magnetic properties is essential in order to design new magnetic materials. The present investigation was carried out to throw light on the effect of $\mathrm{Cr}^{3+}$ ion concentration on the structural and magnetic properties of the Co-ferrite nanoparticles synthesized using sol gel method.

\section{Experimental Details}

\subsection{Synthesis of $\mathrm{Cr}_{x} \mathrm{CoFe}_{2-x} \mathrm{O}_{4}$}

$\mathrm{Cr}^{3+}$ substituted $\mathrm{CoFe}_{2} \mathrm{O}_{4}$ ferrite with a chemical formula $\mathrm{Cr}_{x} \mathrm{CoFe}_{2-x} \mathrm{O}_{4}$ (where, $x=0.0 .0 .1,0.2,0.3,0.4$ and 0.5 ) have been synthesized via sol-gel method. The analytical grade $\mathrm{Fe}\left(\mathrm{NO}_{3}\right)_{3} \cdot 9 \mathrm{H}_{2} \mathrm{O}, \mathrm{Co}\left(\mathrm{NO}_{3}\right)_{2} \cdot 6 \mathrm{H}_{2} \mathrm{O}, \mathrm{Cr}\left(\mathrm{NO}_{3}\right)_{3} \cdot 9 \mathrm{H}_{2} \mathrm{O}$ and $\mathrm{C}_{6} \mathrm{H}_{8} \mathrm{O}_{7} \cdot \mathrm{H}_{2} \mathrm{O}$ (hydrated citric acid) were used as precursor materials. These chemicals were weighed in desired stoichiometric proportion and completely dissolved in minimum quantity of distilled water. This solution was then added to citric acid in such a way that in the final sample, the molar ratio of these nitrates and citric acid become 1:1 [12]. A small amount of ammonia was drop-wise added to achieve $\mathrm{pH}=7$ by stirring the solution simultaneously using a magnetic stirrer. Condensation reaction occurs between the adjacent metal nitrates and the molecules of citrates yielding a polymer network in colloidal dimensions known as sol. The stirring is continued for one hour. The solution was evaporated by intensive stirring and heating for 1 hour at $100^{\circ} \mathrm{C}$ and kept at this temperature until the sol turned into a gel. The gel was then heated at $150^{\circ} \mathrm{C}$ for auto-combustion to take place. The resulting powder is crushed in an agate mortar to obtain the nanoferrite particles and was sintered at $900^{\circ} \mathrm{C}$ for 3 hours.

\subsection{Characterization Techniques}

Structural identification and phase analysis of Cr-Co ferrites were carried out by XRD studies using Bruker D8 advance (Model No. 204795) X-ray Diffractometer. The XRD measurements were performed by CuK $\alpha$ radiation ( $\lambda=1.5406 \AA$ ) in the range of $2 \theta=20^{\circ}$ to $80^{\circ}$ in the steps of $0.02^{\circ}$. Spinel types of crystal structure without having any other intermediate phases and high purity levels of constituent powders were confirmed by XRD study. The Fourier Transform Infrared (FTIR) spectra of the obtained powders were recorded using FTIR spectrometer (Thermo electron corporation, Serial No: AEU0500303) in the wave number range $4000 \mathrm{~cm}^{-1}$ to 400 $\mathrm{cm}^{-1}$ using $\mathrm{KBr}$ pellets to ratify the spinel structure of the samples. The surface morphology of the samples were examined using Scanning Electron Microscope (SEM). Transmission Electron Microscope (TEM) technique along with Energy Dispersive Spectrum (EDS) was used in order to investigate the nanostructure and elemental composition of the product material. The sample for TEM was prepared by placing a drop of ethanol suspension of the nanoparticles on carbon-coated Cu TEM grids. The grids were examined using a transmission electron 
microscope (FEI Tecnai G2 S-Twin $200 \mathrm{kV}$ ). In order to study the magnetic properties, VSM (Lake Shore model 7407) analysis was used at a room temperature with maximum applied magnetic field of $15 \mathrm{kG}$.

\section{Results \& Discussion}

\subsection{X-Ray Diffraction (XRD) Analysis}

The phase and purity of the synthesized Cr-Co ferrite nanopowders were examined by X-ray diffraction (XRD) patterns and are shown in Figure 1. These patterns of the samples suggest the formation of spinel cubic structure. According to the cubic crystal structure of spinel phase, the value of lattice parameter " $a$ " determined from the most intense (3 11 ) reflection of XRD pattern using the following equation [13] and values are listed in Table 1.

$$
a=d_{h k l} /\left(\sqrt{h^{2}+k^{2}+l^{2}}\right)
$$

where " $a$ " is lattice constant, $d_{h k l}$ is inter-planar distance for $h k l$ plane. The variation of the lattice constant with $\mathrm{Cr}^{3+}$ attentiveness (x) does not obey Vegard's law. The slight variation in lattice constant may be due to slight difference in the ionic radii of $\mathrm{Cr}^{3+}(0.63 \AA)$ and $\mathrm{Fe}^{3+}(0.64 \AA)$ ions [14] [15]. Further nonlinear behavior of lattice constant with $\mathrm{Cr}^{3+}$ ion concentration reported in the literature is for the systems which are not completely normal or inverse [16].

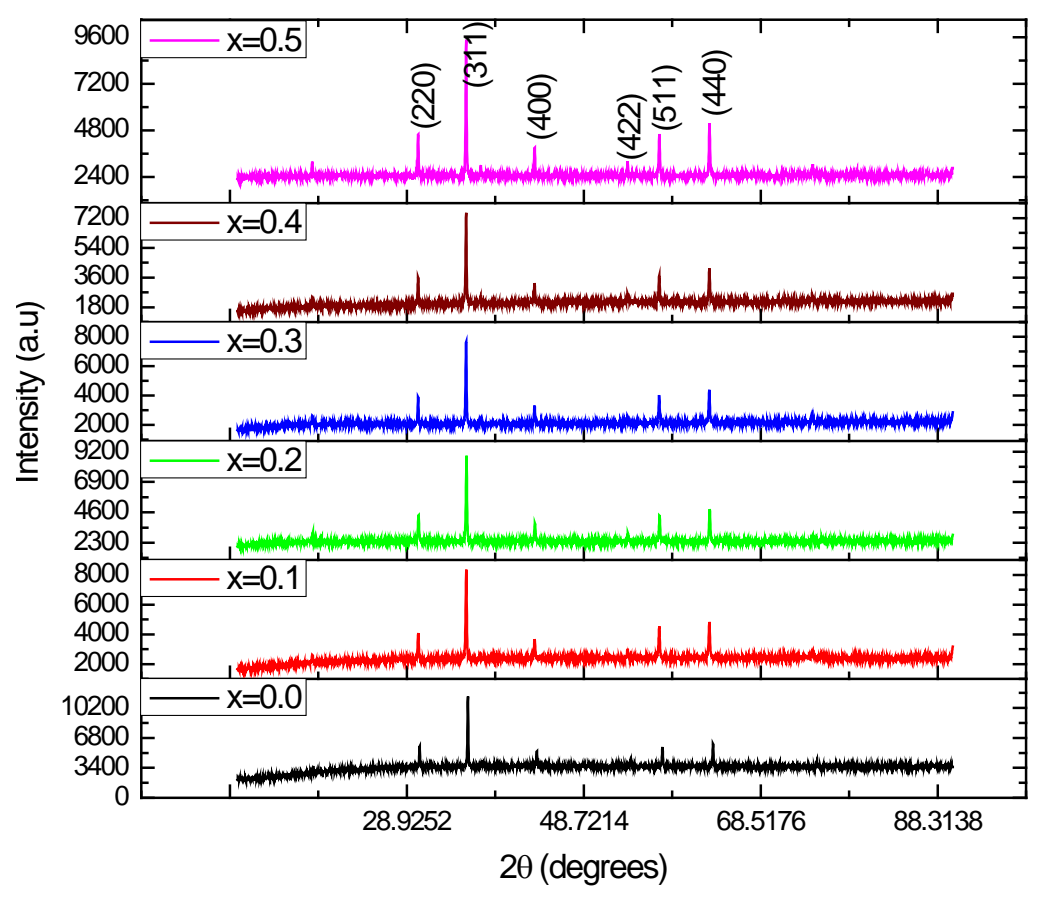

Figure 1. The XRD patterns for $\mathrm{Cr}_{x} \mathrm{CoFe}_{2-x} \mathrm{O}_{4}$ with $x=0.0,0.1,0.2,0.3,0.4$ and 0.5 .

Table 1. Structural parameters of $\mathrm{Cr}_{x} \mathrm{CoFe}_{2-x} \mathrm{O}_{4}(x=0.0$ to 0.5$)$.

\begin{tabular}{|c|c|c|c|c|c|c|c|}
\hline S. No & Cr content $(x)$ & $d(\mathrm{~nm})$ & a $(\AA)$ & $\rho_{x}(g / c c)$ & $\rho_{b}(\mathrm{~g} / \mathrm{cc})$ & $\% P$ & $S\left(\mathrm{~m}^{2} / \mathrm{g}\right)$ \\
\hline 1 & $\mathrm{x}=0.0$ & 75 & 8.3200 & 5.410 & 4.46 & 17.4 & 17.7 \\
\hline 2 & $\mathrm{x}=0.1$ & 56 & 8.3545 & 5.328 & 3.29 & 38.2 & 32.6 \\
\hline 3 & $\mathrm{x}=0.2$ & 57 & 8.3524 & 5.332 & 3.27 & 38.6 & 32.2 \\
\hline 4 & $x=0.3$ & 62 & 8.3624 & 5.304 & 2.73 & 48.5 & 35.5 \\
\hline 5 & $x=0.4$ & 65 & 8.3621 & 5.296 & 3.38 & 36.1 & 27.3 \\
\hline 6 & $x=0.5$ & 64 & 8.3604 & 5.288 & 3.40 & 35.7 & 27.6 \\
\hline
\end{tabular}


The average crystallite size of all the samples was evaluated by measuring the full width half maxima (FWHM) of the most intense peak (3 11 1) from XRD pattern and by using the following Debye-Scherer's formula.

$$
D=K \lambda / \beta \operatorname{Cos} \theta
$$

where, $D$ is the crystallite size, $\lambda$ is the wavelength of incident X-rays, $\theta$ is the diffraction angle and $\beta$ is the full-width at half-maximum (FWHM), and $K$ is the shape factor, about 0.9 for spherical shaped particles. The analysis revealed that the crystallite sizes are in the range of $56-75 \mathrm{~nm}$ andthe size of the particle decreases with the increase of $\mathrm{Cr}^{3+}$ ion concentration.

The other structural parameters such as X-ray density $\left(\rho_{x}\right)$, bulk density $\left(\rho_{b}\right)$, porosity $(P)$ and surface area $(S)$ were calculated from XRD data using the following equations. The calculated values are furnished in the Table 1.

$$
\begin{aligned}
& \rho_{x}=Z M / N V \\
& \rho_{b}=m /\left(\pi r^{2} h\right) \\
& P(\%)=\left(1-\rho_{b} / \rho_{x}\right) \times 100 \\
& S=\frac{6000}{(\rho x * d)}
\end{aligned}
$$

where, $Z$ is number of atoms per unit cell, $M$ is the molecular weight of the composition, $N$ is the Avogadro's number and $m, r$, and $h$ are mass, radius, and thickness of the pellet of sample respectively.

$\mathrm{X}$-ray density also decreased with increase in Chromium content $(x)$. The decrease in X-ray density is attributed to the decrease in mass overtakes the decrease in volume. Also due to difference in their atomic weight ( $\mathrm{Fe}=55.845$ a.m.u. and $\mathrm{Cr}=51.996$ a.m.u.) respectively.

It is observed that the X-ray density $\rho_{x}$ of each sample is greater than the corresponding bulk density $\left(\rho_{b}\right)$. This may be due to some unavoidable pores created during sample preparation and sintering process [17].

Using the values of lattice constant (a), the distance between magnetic ions (ion jump lengths) available in te-

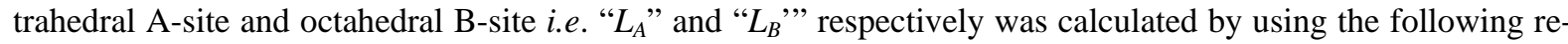
lations [18].

$$
\begin{aligned}
L_{A} & =(\sqrt{3} / 4) a \\
L_{B} & =(\sqrt{2} / 4) a
\end{aligned}
$$

Calculated values of ion jump lengths $\left(L_{A}\right.$ and $L_{B}$ ) are given in Table 2. The behavior of ion jump lengths with Chromium concentration $(x)$ is attributed to the variation of lattice constant with the $\mathrm{Cr}$ content $(x)$.

\subsection{Fourier Transform Infrared Spectroscopy (FTIR) Analysis}

Fourier transform infrared (FTIR) studies were carried out to ascertain the metal-oxygen bonding. FTIR spectrums of the investigated samples are shown in Figure 2. Infrared spectroscopy study supported the formation of Cr-Co spinel ferrite in the nanocrystalline form with enlightening two strong absorption bands around $600 \mathrm{~cm}^{-1}$ and $400 \mathrm{~cm}^{-1}$ that are the common features of all spinel ferrites [19]. The typical bands of spinel structure are attributed to the stretching vibrations of the unit cell of the spinel in the tetrahedral (A) site and the metal-oxygen vibration in the octahedral (B) site. This result is also in agreement with that of Waldron (Waldron 1955), assigned the high frequency band to the tetrahedral group (around $600 \mathrm{~cm}^{-1}$ ) and low frequency band to the octahedral group (around $450 \mathrm{~cm}^{-1}$ ) [20]. These absorption bands are highly sensitive to changes in interaction between oxygen and cations, as well as to the size of the obtained nano-particles [21]. The broadening of the spectral band depends on the statistical distribution of cations over A and B sites. The vibration frequency depends on the cation mass, cation-oxygen distance and bending force [22]. From Figure 2 and Table 3, it is clear that with $\mathrm{Cr}^{3+}$ ion doping, the absorption band $v 2$ shifts to the higher frequency side which indicates that the occupancy of $\mathrm{Cr}^{3+}$ ions at octahedral site (B-site). The replacement of $\mathrm{Fe}^{3+}$ ions with $\mathrm{Cr}^{3+}$ ions at octahedral sites which have smaller ionic radius, lower atomic mass, increased bond length at B-sites and change in the lattice 
Table 2. Variation of hopping lengths $\left(L_{A}\right.$ and $\left.L_{B}\right)$ with Cr content $x$.

\begin{tabular}{cccc}
\hline S. No & Cr content $(\boldsymbol{x})$ & $\boldsymbol{L}_{A}(\AA)$ & $\boldsymbol{L}_{B}(\AA)$ \\
\hline 1 & $x=0.0$ & 3.6030 & 2.9400 \\
2 & $x=0.1$ & 3.6175 & 2.9530 \\
3 & $x=0.2$ & 3.6164 & 2.9520 \\
4 & $x=0.3$ & 3.6209 & 2.9561 \\
5 & $x=0.4$ & 3.6207 & 2.9560 \\
6 & $x=0.5$ & 3.6200 & 2.9554 \\
\hline
\end{tabular}

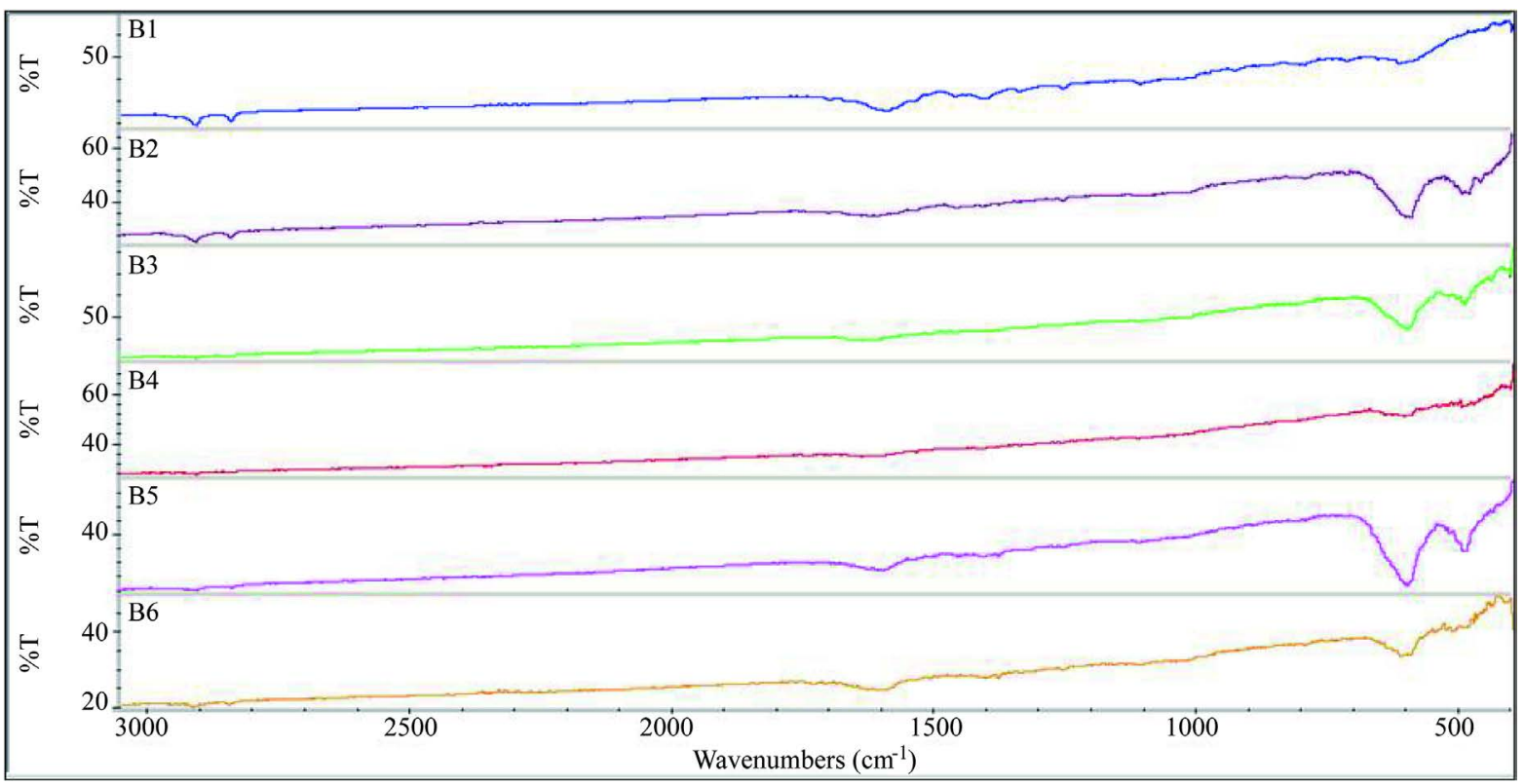

Figure 2. FTIR spectra for $\mathrm{Cr}_{x} \mathrm{CoFe}_{2-x} \mathrm{O}_{4}$ with $x=0.0$ (B1), 0.1 (B2), 0.2 (B3), 0.3 (B4), 0.4 (B5) and 0.5 (B6).

Table 3. Data on the position of FTIR absorption bands $\left(v_{1}, v_{2}\right)$ and force constants.

\begin{tabular}{cccccc}
\hline S. No & Cr content $(\boldsymbol{x})$ & $\boldsymbol{v}_{\mathbf{1}}\left(\mathrm{cm}^{-1}\right)$ & $\boldsymbol{v}_{\mathbf{2}}\left(\mathrm{cm}^{-1}\right)$ & $K_{\mathbf{t}} \times 10^{5}(\mathrm{dynes} / \mathrm{cm})$ & $K_{\boldsymbol{O}} \times 10^{5}(\mathrm{dynes} / \mathrm{cm})$ \\
\hline 1 & $x=0.0$ & 618 & 455 & 2.772 & 1.505 \\
2 & $x=0.1$ & 607 & 485 & 2.674 & 1.710 \\
3 & $x=0.2$ & 604 & 494 & 2.648 & 1.774 \\
4 & $x=0.3$ & 610 & 491 & 2.706 & 1.750 \\
5 & $x=0.4$ & 603 & 497 & 2.646 & 1.797 \\
6 & $x=0.5$ & 618 & 497 & 2.778 & 1.795 \\
\hline
\end{tabular}

constant are the considerable reasons of the observed shift in the band position $\left(v_{2}\right)$ with increasing Cr concentration.

The values of the force constants of the ions at the tetrahedral site $\left(K_{t}\right)$ and octahedral site $\left(K_{O}\right)$ are calculated using the following formula [23].

$$
K=4 \pi^{2} c^{2} v^{2} \mu
$$

where $c$ is the velocity of light, $v$ is the vibration frequency of the A- and B-sites and $\mu$ is the reduced mass of the $\mathrm{Fe}^{3+}$ and $\mathrm{O}^{2-}$ ions which is nearly equal to $2.601 \times 10^{-23} \mathrm{~g}$. Table 3 shows variation of $K_{t}$ and $K_{o}$ with $\mathrm{Cr}$ content. It can be observed that the trend of both $K_{t}$ and $K_{o}$ is increasing with Cr content. One may interpret this behavior due to the increase in bond lengths of both $\mathrm{A}$ and B-sites with Cr concentration. 


\subsection{Scanning Electron Microscope (SEM) Analysis}

SEM images of all the $\mathrm{Cr}_{x} \mathrm{CoFe}_{2-x} \mathrm{O}_{4}(x=0.0,0.1,0.2,0.3,0.4,0.5)$ ferrite samples are shown in Figure 3, reflecting homogeneous grain size distribution, well packed and are almost crack free. Few agglomerates were found in the composition $x=0.0$. The appearance of these agglomerates may be attributed to sintering process as a result of chemical reaction. Magnetic forces or even relatively weak Vander Waals bonds might be responsible to hold these agglomerates together [21].

\subsection{Transmission Electron Microscope (TEM) Analysis}

TEM was employed to visualize the size, shape and to confirm the nanocrystalline nature of the Cr-Co ferrite particles. Figure 4(a) shows the TEM micrographs of $\mathrm{Cr}_{0.2} \mathrm{CoFe}_{1.8} \mathrm{O}_{4}$ ferrite nanoparticles. TEM micrograph shows that the particles are formed in a controlled manner and the variation in the size of their particles is very small. The sizes of the nanocrystals determined by TEM were in good agreement with the size calculated from peak broadening in X-ray diffractograms. High-resolution TEM images often exhibit crystal lattice, as it is evident for a nanoparticles of incur ferrite sample. The HRTEM image of $\mathrm{Cr}_{0.2} \mathrm{CoFe}_{1.8} \mathrm{O}_{4}$ nanoparticle is presented in Figure 4(b). The micrograph reveals highly ordered lattice fringes with a fringe separation of $2.53 \AA$, which corresponds to (3 1 1) lattice planes. This value agrees well with that of $2.52 \AA$ determined from the analysis of the XRD pattern. The selected area electron diffraction (SAED) pattern of $\mathrm{Cr}_{0.2} \mathrm{CoFe}_{1.8} \mathrm{O}_{4}$ sample is shown in Figure 4(c). The SAED pattern consists of concentric rings with bright spots over the rings. This feature indicates the samples are polycrystalline in nature. As anticipated, the spotted appearance of the diffraction rings is due to high crystallinity of the obtained nanoparticles. Similar observation has also been reported earlier in the literature [24]. The reason for making EDAX characterization was to ratify the purity and surety of the chemical composition. A representative Energy dispersive analysis of X-rays (EDAX) pattern of $\mathrm{Cr}_{0.2} \mathrm{CoFe}_{1.8} \mathrm{O}_{4}$ is shown in Figure 4(d). The ED pattern reflects that these nanoparticles are well crystallized. The EDAX spectrum revealed that the darker particles contain $\mathrm{Co}, \mathrm{Cr}, \mathrm{Fe}$ and $\mathrm{O}$ as the major elements in the material. The results of EDAX confirm the expected stoichiometry and results suggest that the precursors have fully undergone the chemical reaction to form the expected ferrite composition.

\subsection{M-H Loop Analysis}

The magnetization measurements for the Cr-Co ferrite samples carried out using vibrating sample magnetometer
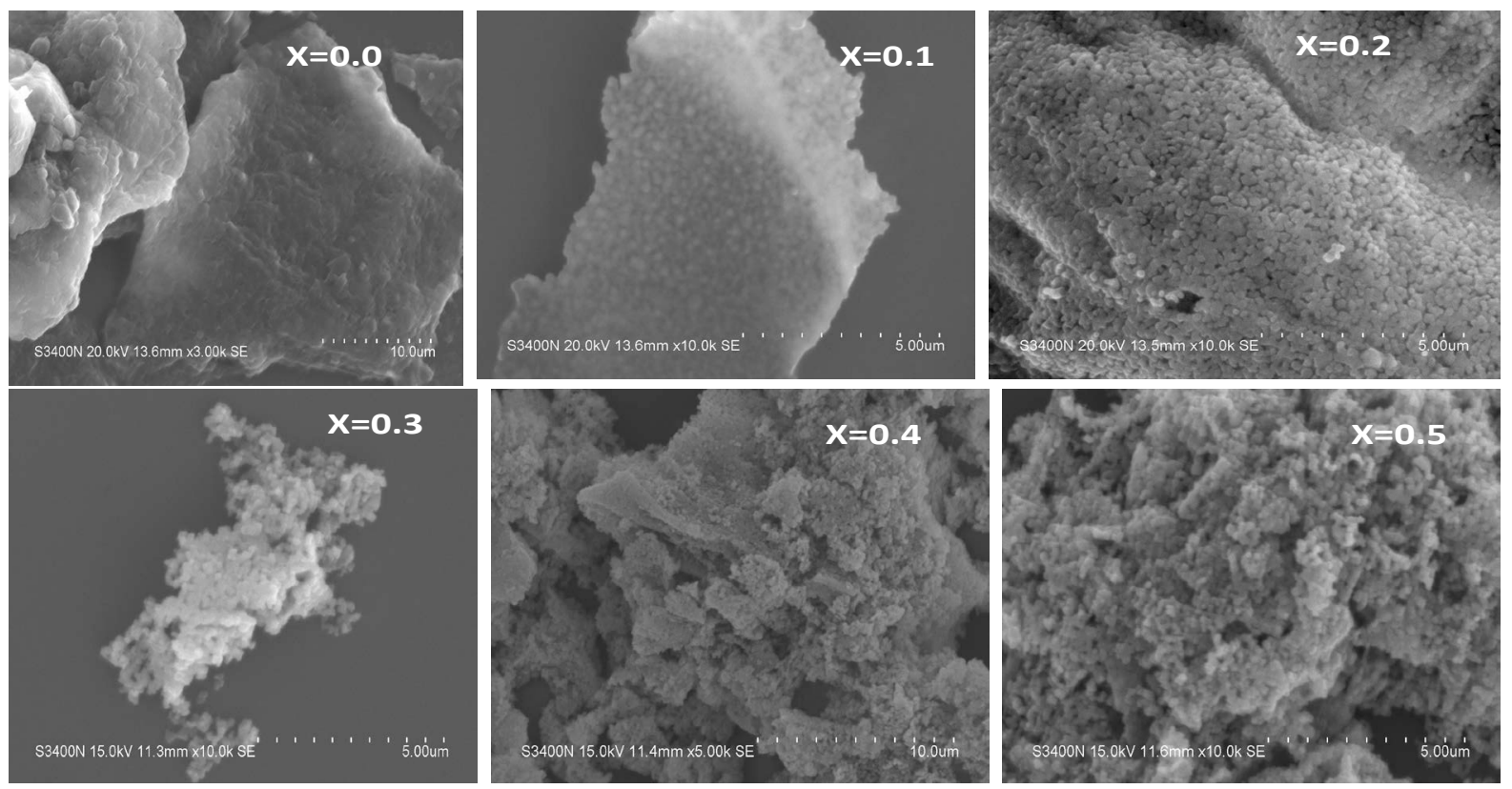

Figure 3. SEM micrographs of $\mathrm{Cr}_{x} \mathrm{CoFe}_{2-x} \mathrm{O}_{4}(x=0.0$ - 0.5) ferrites. 


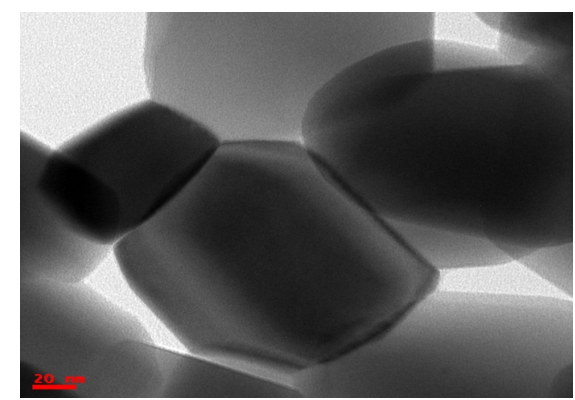

(a)

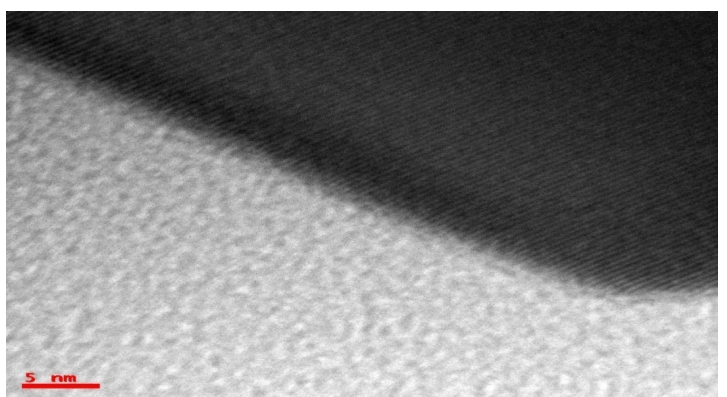

(b)

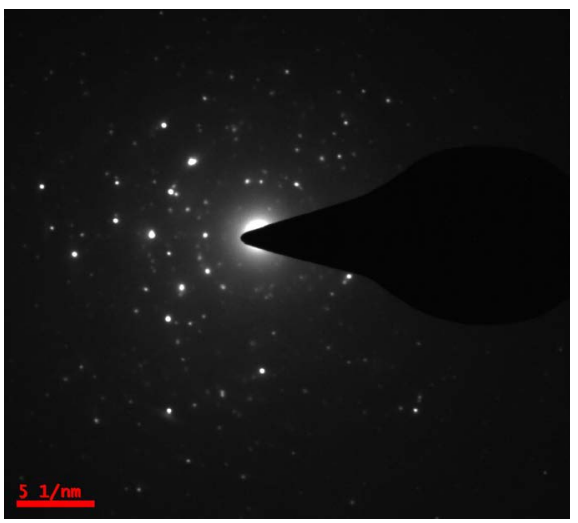

(c)

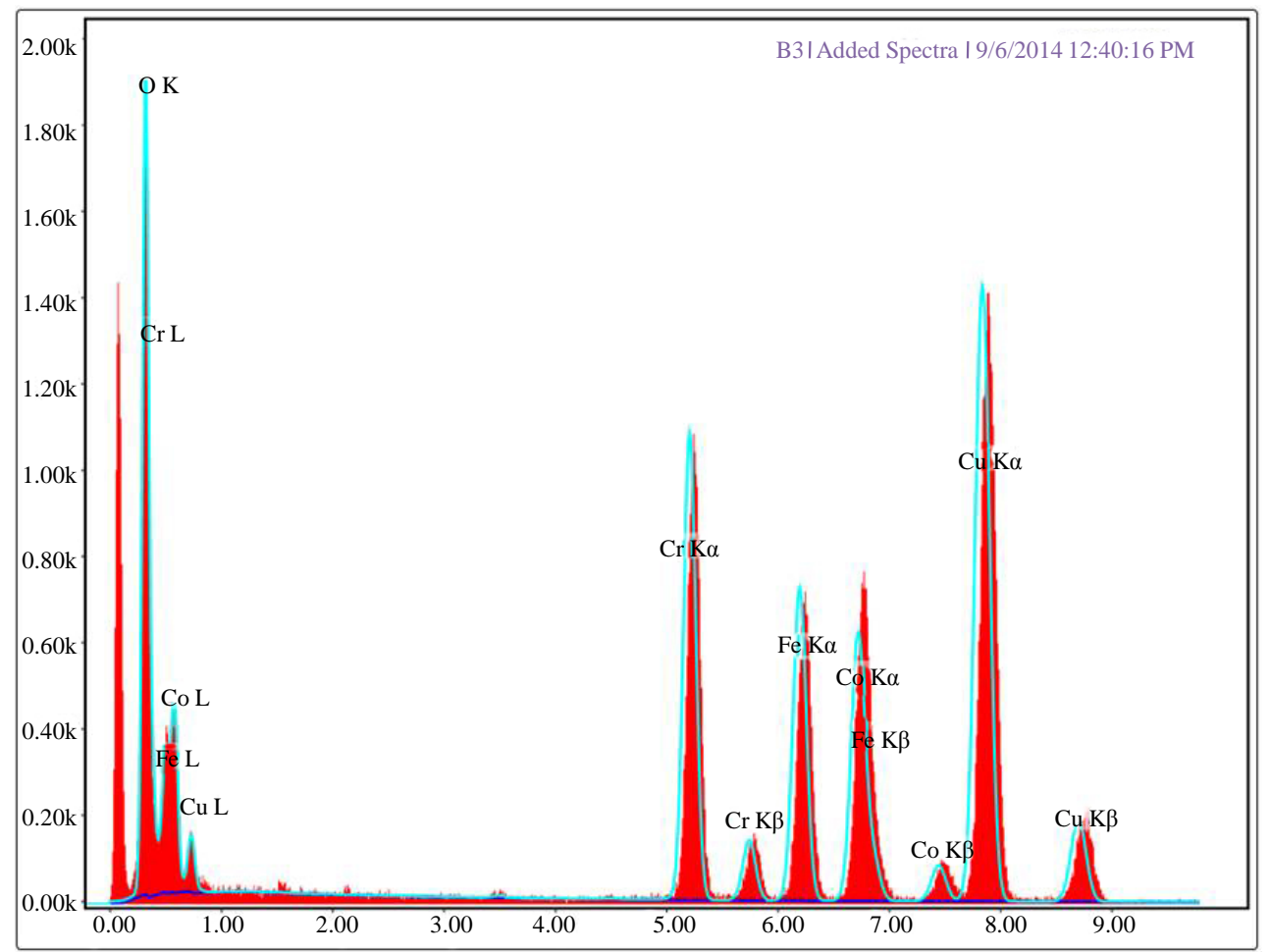

Lsec:30.0 25Cnts $2.540 \mathrm{keV} \quad$ Det:Apollo XLT LightShield

(d)

Figure 4. TEM images of $\mathrm{Cr}_{x} \mathrm{CoFe}_{2-x} \mathrm{O}_{4}(x=0.2)$ sample. (a) Transmission electron micrograph of $\mathrm{Cr}_{x} \mathrm{CoFe}_{2-x} \mathrm{O}_{4}(x=0.2)$ sample; (b) HRTEM image; (c) Corresponding SAED pattern of the sample; and (d) EDAX spectrum. 
(VSM) at room temperature with an applied magnetic field $15 \mathrm{kG}$. The $\mathrm{M}-\mathrm{H}$ loops of all Cr-Co ferrite samples are shown in Figure 5(a). The main magnetic data like saturation magnetization $\left(M_{S}\right)$, coercivity $\left(H_{C}\right)$, remanence magnetization $\left(M_{r}\right)$, squareness ratio $\left(M_{r} / M_{S}\right)$, anisotropy constant $\left(K_{1}\right)$ and magnetic moment $\left(n_{B}\right)$ of all the samples are listed in Table 4. It was observed that initially Co ferrite $(x=0.0)$ showing maximum saturation magnetization $41.15 \mathrm{emu} / \mathrm{g}$. As Chromium is doped into the sample (at $x=0.1$ ), the saturation magnetization is abruptly dropped from $41.55 \mathrm{emu} / \mathrm{g}$ to $11.86 \mathrm{emu} / \mathrm{g}$, thereafter the saturation magnetization slightly increased for the samples from $x=0.2$ to $x=0.5$. According to Neel's two sublattice model, there are three kinds of super exchange interactions in spinel ferrite i.e., A-A, B-B and A-B interaction. The A-B interaction strength is large than A-A and B-B. The net magnetic moment $M=M_{B}-M_{A}$ and the large $\mathrm{M}$ results in higher saturation magnetization. The substitution of low magnetic $\mathrm{Cr}^{3+}$ ion $(3 \mu \mathrm{B})$, which has a preferential B site occupancy results in the reduction of super-exchange interaction between $\mathrm{A}$ and $\mathrm{B}$ sites. The decrease in saturation magnetization value for $x=0.1$ is due to migration of $\mathrm{Fe}^{3+}$ ions from B site to A site, the magnetization of B site $\left(M_{B}\right)$ decreases while the magnetization of A site $\left(M_{A}\right)$ increases. Therefore the net magnetization $\left(M_{B}-M_{A}\right)$ decreases [25]. As the grain size becomes smaller, the magnetization direction of the ultra-fine ferrite powder cannot be fixed as in large crystals, but fluctuates spontaneously [26]. The slight increase in saturation magnetization values for the samples above $x=0.1$ is due to the canting and the non-co linearity of the spin [27]. Figure 5(b) shows the variation of saturation magnetization with Cr-concentration $(x)$.

The value of coercivity decreased from $377 \mathrm{G}$ to $14.25 \mathrm{G}$ for the sample $x=0.1$ and then slightly increased for the samples from $x=0.2$ to $x=0.5$. The decrease in coercivity value may be due to the decrease in anisotropy field which in turn decreases the domain wall energy [28] [29]. Other considerable factors that influence coercivity are micro-strain, magneto crystallinity, magnetic particle morphology, size distribution, porosity, magnetic domain size [30]. The change in the coercive force $\left(H_{c}\right)$ with $\mathrm{Cr}$ ion concentration is shown in Figure 5(c).

The magneto crystalline anisotropy constant is calculated from the saturation magnetization and coercivity of hysteresis loops by using following relation [31].

$$
H_{C}=\frac{0.98 K_{1}}{M_{s}}
$$

The change in $K_{1}$ can be estimated qualitatively by applying the single ion anisotropy model which shows that $\mathrm{Fe}^{3+}$ ions in A and B-sites contribute to the anisotropy energy. The $\mathrm{Fe}^{3+}$ ion occupying A-site has a positive value of anisotropy constant while the one occupying B-site has a negative value twice as large as the positive value at A-site. As $\mathrm{Fe}^{3+}$ ions are replaced by $\mathrm{Cr}^{3+}$ ions, that have low anisotropy constant, the decrease in $K_{1}$ at B-site should be faster than that at A-site. Thus, the net value of $K_{1}$ decreases with the substitution of $\mathrm{Cr}^{3+}$ ions in the samples. This behavior is in agreement with the observation noted by $\mathrm{H}$. Bahiraei et al. on $\mathrm{Al}$ doped MgCuZn ferrites [32]. The magnetic moment $\left(n_{B}\right)$ per formula unit in Bhor magneton was calculated by using following equation [33].

$$
n_{B}\left(\mu_{B}\right)=\frac{M * M_{s}}{5585}
$$

where, $M$ is the molecular weight of the sample and $M_{s}$ is the saturation magnetization in emu/g. The calculated values of the magnetic moment $\left(\eta_{B}\right)$ are shown in Table 4. It is evident from Table 4 . That $n_{B}$ is decreases with the substitution of $\mathrm{Cr}$ content in these samples which is quite consistent with the behavior of saturation magnetization.

\section{Conclusion}

Cr substituted Co-ferrites with the chemical formula $\mathrm{Cr}_{x} \mathrm{CoFe}_{2-x} \mathrm{O}_{4}(x=0.0-0.5)$ synthesized by sol-gel method. The X-ray diffraction analysis confirmed the formation of single phase spinel structure. FTIR spectra exhibit the shifting of the absorption bands towards higher frequency with the increase of Cr-concentration. SEM micrographs show uniform particle distribution. TEM analysis reveals the cubic shape; less agglomerated particles consist of polycrystalline nature in the resultant ferrite samples. The magnetic properties of the Cr-Co ferrite samples suggest that the synthesized sample converts from hard to soft ferrite with increasing $\mathrm{Cr}^{3+}$ concentration. 


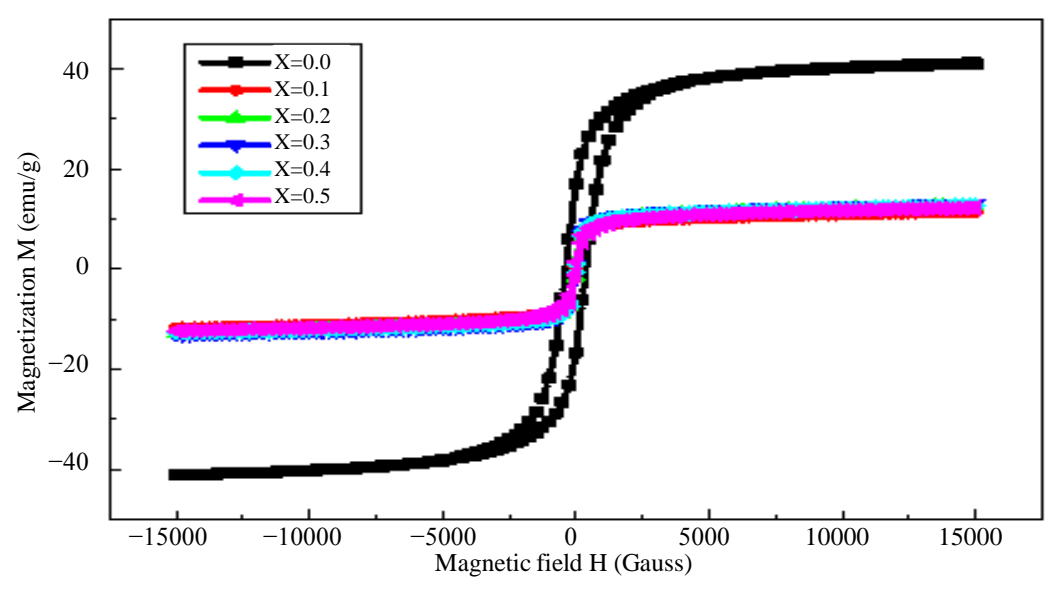

(a)

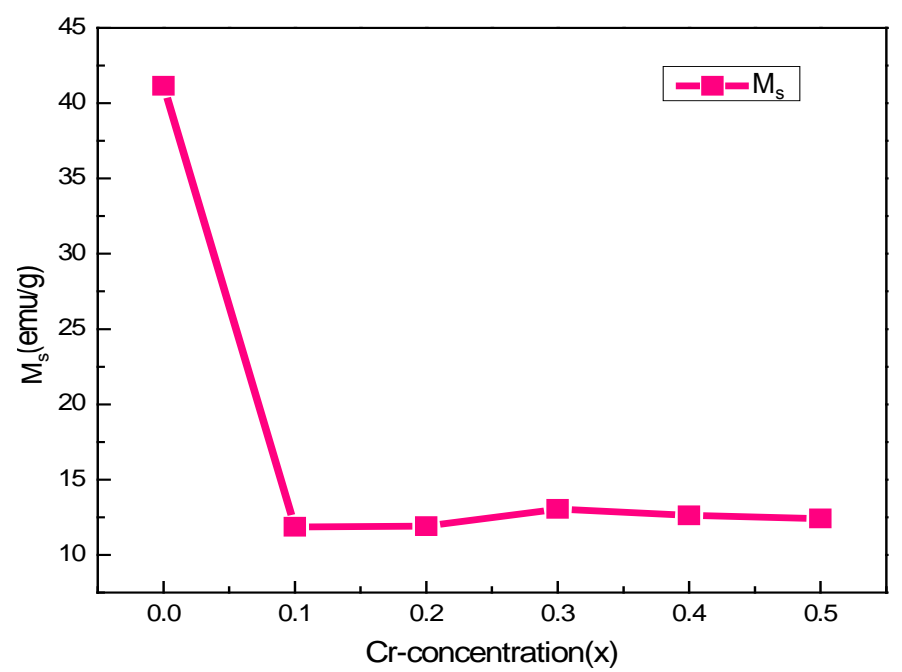

(b)

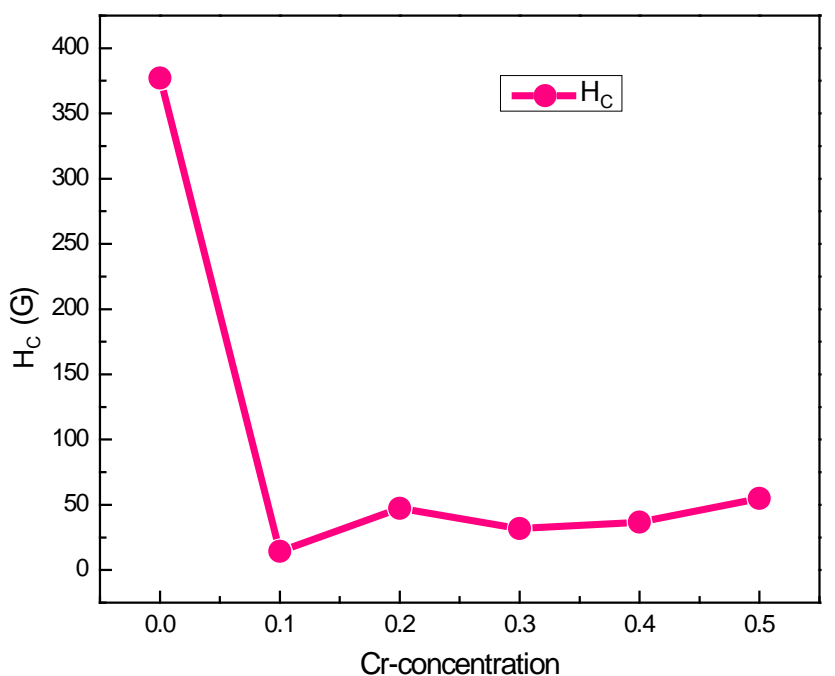

(c)

Figure 5. (a) M-H loops for $\mathrm{Cr}_{x} \mathrm{CoFe}_{2-x} \mathrm{O}_{4}$ samples; (b) Variation of saturation magnetization $\left(M_{s}\right)$ with $\mathrm{Cr}$ concentration $(x)$; (c) Variation of coercivity $\left(H_{c}\right)$ with $\mathrm{Cr}$ concentration $(x)$. 
Table 4. Magnetic parameters of $\mathrm{Cr}_{x} \mathrm{CoFe}_{2-x} \mathrm{O}_{4}(x=0.0$ to 0.5$)$ samples.

\begin{tabular}{cccccccc}
\hline S. No & Cr content $(\boldsymbol{x})$ & $\boldsymbol{M}_{\boldsymbol{s}}(\mathbf{e m u} / \mathbf{g})$ & $\boldsymbol{H}_{\boldsymbol{c}}(\mathbf{G})$ & $\boldsymbol{M}_{\boldsymbol{r}}(\mathbf{e m u} / \mathbf{g})$ & $\boldsymbol{M}_{\boldsymbol{r}} / \boldsymbol{M}_{\boldsymbol{s}}$ & $\boldsymbol{n}_{\boldsymbol{B}}\left(\boldsymbol{\mu}_{\boldsymbol{B}}\right)$ & $\boldsymbol{K}_{\mathbf{1}}(\mathbf{e r g} / \mathbf{G})$ \\
\hline 1 & $x=0.0$ & 41.155 & 377.00 & 17.097 & 0.415 & 1.729 & 15832.08 \\
2 & $x=0.1$ & 11.86 & 14.25 & 0.353 & 0.029 & 0.497 & 172.45 \\
3 & $x=0.2$ & 11.90 & 47.29 & 1.496 & 0.126 & 0.498 & 574.23 \\
4 & $x=0.3$ & 13.05 & 31.71 & 1.002 & 0.077 & 0.546 & 422.26 \\
5 & $x=0.4$ & 12.63 & 36.57 & 1.151 & 0.091 & 0.527 & 471.31 \\
6 & $x=0.5$ & 12.41 & 54.87 & 1.486 & 0.120 & 0.517 & 694.83 \\
\hline
\end{tabular}

The substitution of Chromium has shown the striking impact on the structural and magnetic properties of the $\mathrm{Cr}_{x} \mathrm{CoFe}_{2-x} \mathrm{O}_{4}$ ferrite system.

\section{References}

[1] Mustafa, G., Islam, M.U., Zhang, W., Jamil, Y., Anwar, A.W., Hussain, M. and Ahmad, M. (2015) Investigation of Structural and Magnetic Properties of $\mathrm{Ce}^{3+}$-Substituted Nanosized Co-Cr Ferrites for a Variety of Applications. Journal of Alloys and Compounds, 618, 428-436. http://dx.doi.org/10.1016/j.jallcom.2014.07.132

[2] Rezlescu, N., Rezlescu, E., Popa, P.D., Doroftei, C. and Ignat, M. (2014) Scandium Substituted Nickel-Cobalt Ferrite Nanoparticles for Catalyst Applications. Applied Catalysis B: Environmental, 158, 70-75. http://dx.doi.org/10.1016/j.apcatb.2014.03.052

[3] Sharma, R.K., et al. (2005) Synthesis of Chromium Substituted Nano Particles of Cobalt Zinc Ferrites by Coprecipitation. Materials Letters, 59, 3402-3405. http://dx.doi.org/10.1016/j.matlet.2005.06.004

[4] Mathew, D.S. and Juang, R.S. (2007) An Overview of the Structure and Magnetism of Spinel Ferrite Nanoparticles and Their Synthesis in Microemulsions. Chemical Engineering Journal, 129, 51-65. http://dx.doi.org/10.1016/j.cej.2006.11.001

[5] Moya, C., del Puerto Morales, M., Batlle, X. and Labarta, A. (2015) Tuning the Magnetic Properties of Co-Ferrite Nanoparticles through the 1,2-Hexadecanediol Concentration in the Reaction Mixture. Physical Chemistry Chemical Physics, 17, 13143-13149. http://dx.doi.org/10.1039/C5CP01052G

[6] Keluskar, S.H., Tangsali, R.B., Naik, G.K. and Budkuley, J.S. (2006) High Permeability of Low Loss Mn-Zn Ferrite Obtained by Sintering Nanoparticle Mn-Zn Ferrite. Journal of Magnetism and Magnetic Materials, 305, $296-303$. http://dx.doi.org/10.1016/j.jmmm.2006.01.018

[7] Kuznetsov, M.V., Barquín, L.F., Pankhurst, Q.A. and Parkin, I.P. (1999) Self-Propagating High-Temperature Synthesis of Barium-Chromium Ferrites $\mathrm{BaFe}_{12-\mathrm{x}} \mathrm{Cr}_{\mathrm{x}} \mathrm{O}_{19}$. Journal of Physics D: Applied Physics, 32, 2590. http://dx.doi.org/10.1088/0022-3727/32/20/302

[8] Zahraei, M., Monshi, A., del Puerto Morales, M., Shahbazi-Gahrouei, D., Amirnasr, M. and Behdadfar, B. (2015) Hydrothermal Synthesis of Fine Stabilized Superparamagnetic Nanoparticles of $\mathrm{Zn}^{2+}$ Substituted Manganese Ferrite. Journal of Magnetism and Magnetic Materials, 393, 429-436. http://dx.doi.org/10.1016/j.jmmm.2015.06.006

[9] Hassan, A., Khan, M.A., Shahid, M., Asghar, M., Shakir, I., Naseem, S. and Warsi, M.F. (2015) Nanocrystalline $\mathrm{Zn}_{1-\mathrm{x}} \mathrm{Co}_{0.5 \mathrm{x}} \mathrm{Ni}_{0.5 \mathrm{x}} \mathrm{Fe}_{2} \mathrm{O}_{4}$ Ferrites: Fabrication via Co-Precipitation Route with Enhanced Magnetic and Electrical Properties. Journal of Magnetism and Magnetic Materials, 393, 56-61. http://dx.doi.org/10.1016/j.jmmm.2015.05.033

[10] Sen, R., Jain, P., Patidar, R., Srivastava, S., Rana, R.S. and Gupta, N. (2015) Synthesis and Characterization of Nickel Ferrite $\left(\mathrm{NiFe}_{2} \mathrm{O}_{4}\right)$ Nanoparticles Prepared by Sol-Gel Method. Materials Today: Proceedings, 2, 3750.

[11] Hankare, P.P., Patil, R.P., Sankpal, U.B., et al. (2009) Investigation of Structural and Magnetic Properties of Nanocrystalline Manganese Substituted Lithium Ferrites. Journal of Solid State Chemistry, 182, 3217-3221. http://dx.doi.org/10.1016/j.jssc.2009.08.034

[12] Kumar, K.V., Lakshmi, M. and Suresh, M.B. (2013) Structure-Property Correlation of Sol-Gel Processed $\mathrm{Co}_{0.5} \mathrm{Ti}_{0.5} \mathrm{ZnFeO}_{4}$ Ceramic. International Journal of Engineering Research and Applications, 3, 1489.

[13] Krishna, K.R., Ravinder, D., Kumar, K.V. and Lincon, C.A. (2012) Synthesis, XRD \& SEM Studies of Zinc Substitution in Nickel Ferrites by Citrate Gel Technique. World Journal of Condensed Matter Physics, 2, 153-159. http://dx.doi.org/10.4236/wjcmp.2012.23025

[14] Haralkar, S.J., More, S.S., Shirsath, S.E., Kadam, R.H. and Mane, D.R. (2012) Ion Jump Lengths of MN-ZN-AL-FE and MG-ZN-CR-FE Nano-Particles. Indian Streams Research Journal, 2, 1-6.

[15] Zakaria, A.K.M., Nesa, F., Khan, M.S., Yunus, S.M., Khan, N.I., Saha, D.K. and Eriksson, S.G. (2015) Dielectric and 
Electrical Properties of Cr Substituted Mg Ferrites. Journal of Bangladesh Academy of Sciences, 39, 1. http://dx.doi.org/10.3329/jbas.v39i1.23652

[16] Alone, S.T. and Jadav, K.M. (2008) Structural and Magnetic Properties of Zinc- and Aluminum-Substituted Cobalt Ferrite Prepared by Co-Precipitation Method. Pramana-Journal of Physics, 70, 173-181. http://dx.doi.org/10.1007/s12043-008-0015-2

[17] Iqbal, M.J., Ahmad, Z., Meydan, T. and Melikhov, Y. (2012) Physical, Electrical and Magnetic Properties of NanoSized Co-Cr Substituted Magnesium Ferrites. Journal of Applied Physics, 111, Article ID: 033906. http://dx.doi.org/10.1063/1.3676438

[18] Sridhar, R., Ravinder, D. and Kumar, K.V. (2012) Synthesis and Characterization of Copper Substituted Nickel NanoFerrites by Citrate-Gel Technique. Advances in Materials Physics and Chemistry, 2, 192-199. http://dx.doi.org/10.4236/ampc.2012.23029

[19] Hashim, M., Alimuddin, Shirsath, S.E., Kumar, S., Kumar, R., Roy, A.S., Shah, J. and Kotnala, R.K. (2013) Preparation and Characterization Chemistry of Nano-Crystalline Ni-Cu-Zn Ferrite. Journal of Alloys and Compounds, 549, 348-357. http://dx.doi.org/10.1016/j.jallcom.2012.08.039

[20] Waldron, R.D. (1955) Infrared Spectra of Ferrites. Physical Review, 99, 1727-1735. http://dx.doi.org/10.1103/PhysRev.99.1727

[21] Farid, M., Ahmad, I., Aman, S., Kanwal, M., Murtaza, G., Alia, I. and Ishfaq, M. (2015) SEM, FTIR and Dielectric Properties of Cobalt Substituted Spinel Ferrites. Journal of Ovonic Research, 11, 1.

[22] Wahba, A.M. and Mohamed, M.B. (2014) Structural, Magnetic, and Dielectric Properties of Nanocrystalline Cr-Substituted $\mathrm{Co}_{0.8} \mathrm{Ni}_{0.2} \mathrm{Fe}_{2} \mathrm{O}_{4}$ Ferrite. Ceramics International, 40, 6127-6135. http://dx.doi.org/10.1016/j.ceramint.2013.11.064

[23] Bouhadouza, N., Rais, A., Kaoua, S., Moreau, M., Taibi, K. and Addou, A. (2015) Structural and Vibrational Studies of $\mathrm{NiAl}_{x} \mathrm{Fe}_{2-x} \mathrm{O}_{4}$ Ferrites $(0 \leq \mathrm{x} \leq 1)$. Ceramics International, 41, 11687-11692. http://dx.doi.org/10.1016/j.ceramint.2015.05.132

[24] Hankare, P.P., Patil, R.P., Jadhav, A.V., Pandav, R.S., Garadkar, K.M., Sasikala, R. and Tripathi, A.K. (2011) Synthesis and Characterization of Nanocrystalline Ti-Substituted Zn Ferrite. Journal of Alloys and Compounds, 509, 21602163. http://dx.doi.org/10.1016/j.jallcom.2010.10.173

[25] Koseoglu, Y., Baykal, A., Gözüak, F. and Kavas, H. (2009) Structural and Magnetic Properties of $\mathrm{Co}_{x} \mathrm{Zn}_{1-x} \mathrm{Fe}_{2} \mathrm{O}_{4} \mathrm{Na}_{-}$ nocrystals Synthesized by Microwave Method. Polyhedron, 28, 2887-2892. http://dx.doi.org/10.1016/j.poly.2009.06.061

[26] Lee, J.G., Park, J.Y. and Kim, C.S. (1998) Growth of Ultra-Fine Cobalt Ferrite Particles by a Sol-Gel Method and Their Magnetic Properties. Journal of Materials Science, 33, 3965-3968. http://dx.doi.org/10.1023/A:1004696729673

[27] Dar, M.A., Shah, J., Siddiqui, W.A. and Kotnala, R.K. (2014) Study of Structure and Magnetic Properties of Ni-Zn Ferrite Nano-Particles Synthesized via Co-Precipitation and Reverse Micro-Emulsion Technique. Applied Nanoscience, 4, 675-682. http://dx.doi.org/10.1007/s13204-013-0241-x

[28] Singhal, S., Namgyal, T., Bansal, S. and Chandra, K. (2010) Effect of Zn Substitution on the Magnetic Properties of Cobalt Ferrite Nano Particles Prepared via Sol-Gel Route. Journal of Electromagnetic Analysis and Applications, 2, 376-381. http://dx.doi.org/10.4236/jemaa.2010.26049

[29] Singhal, S., Barthwal, S.K. and Chandra, K. (2006) XRD, Magnetic and Mössbauer Spectral Studies of Nano Size Aluminum Substituted Cobalt Ferrites $\left(\mathrm{CoAl}_{x} \mathrm{Fe}_{2-x} \mathrm{O}_{4}\right)$. Journal of Magnetism and Magnetic Materials, 306, $233-240$. http://dx.doi.org/10.1016/j.jmmm.2006.03.023

[30] Anjaneyulu, T., Murthy, P.N., Rafi, S.M., Bademiya, S. and John, G.S. (2013) International Letters of Chemistry, Physics and Astronomy, 14, 37-43.

[31] Kambale, R.C., Shaikh, P.A., Kamble, S.S. and Kolekar, Y.D. (2009) Effect of Cobalt Substitution on Structural, Magnetic and Electric Properties of Nickel Ferrite. Journal of Alloys and Compounds, 478, 599-603. http://dx.doi.org/10.1016/j.jallcom.2008.11.101

[32] Bahiraei, H., Shoushtari, M.Z., Gheisari, K. and Ong, C.K. (2014) The Effect of Non-Magnetic Al ${ }^{3+}$ Ions on the Structure and Electromagnetic Properties of MgCuZn Ferrite. Journal of Magnetism and Magnetic Materials, 371, $29-34$. http://dx.doi.org/10.1016/j.jmmm.2014.07.003

[33] Kumar, G.R., Kumar, K.V. and Venudhar, Y.C. (2012) Synthesis, Structural and Magnetic Properties of Copper Substituted Nickel Ferrites by Sol-Gel Method. Materials Sciences and Applications, 3, 87-91. http://dx.doi.org/10.4236/msa.2012.32013 